\title{
On Development of Suitable Stress Fields for Structural Concrete
}

\author{
by Miguel Fernández Ruiz and Aurelio Muttoni
}

\begin{abstract}
Strut-and-tie models and stress fields are methods that can be used for the dimensioning and detailing of reinforced and prestressed concrete structures as well as for checking existing ones. This paper presents an innovative approach toward the automatic development of stress fields based on a nonlinear finite element analysis. Strut-and-tie models can also be easily developed from the resulting stress fields. Most of the difficulties of the existing methods for developing stress fields and strut-and-tie models based on elastic uncracked analyses are overcome. The application of the proposed approach to the dimensioning of structural members in practical cases is detailed and several comparisons with experimental results are discussed.
\end{abstract}

Keywords: analysis; finite element method; stress fields; structural design; strut-and-tie models.

\section{INTRODUCTION}

Strut-and-tie models and stress fields are methods that are widely used for the design and detailing of structural concrete. Although both methods are based on the lower bound theorem of plasticity, they have very different origins.

The strut-and-tie method is based on the truss analogy. The truss analogy was developed first on the basis of intuition and without a theoretical basis. ${ }^{1,2}$ Its aim was to provide a phenomenological description of the reinforced concrete behavior after cracking, leading to simple physical models suitable to explain its response.

In contrast, stress fields were developed as a direct application of the theory of plasticity. They were successfully applied to the analysis of structural concrete, steel, and masonry. Their first application to reinforced concrete was proposed in 1961 by Drucker, ${ }^{3}$ who developed two stress fields for a simply supported reinforced concrete beam subjected to a point load and to a uniform load (refer to Fig. 1). The development of stress fields based on a rigid-plastic material behavior (known as discontinuous stress fields) occurred mainly in Zürich $^{4-7}$ and Copenhagen, ${ }^{8,9}$ where various studies were developed on their application and applicability.

Since the 1980s, much effort has been done to obtain general methods for developing truss models ${ }^{10,11}$ and stress fields $7,9,12$ in a systematic way and to combine both methods for the analysis of structural concrete.

The use of truss models became increasingly popular in structural concrete practice especially after Schlaich et al. ${ }^{10,11}$ provided some interesting guidelines for the development of such models and examples for their practical application. This approach was named strut-and-tie models by these authors. Ali and White ${ }^{13}$ proposed a different approach for the development of such models.

So far, only a few studies have been conducted on systematic procedures for the development of stress fields. Although a well-established theoretical basis exists, a variety of discontinuous stress fields can be proposed for a structural member

subjected to a given and load combination. Consequently, the development of stress fields remains mainly based on intuition and experience. Recently, a general method for developing stress fields has been proposed by Muttoni et al., ${ }^{12}$ including the serviceability behavior. Despot ${ }^{14}$ has also proposed a finite element approach to the problem with promising results, combining the results of a linear-elastic analysis with a set of self-induced state of stresses to respect the condition of plasticity in the elements.

Although all previous methods constitute an important step forward toward the systematic use of truss models and stress fields, they present certain limitations. This paper reviews the different methods and proposes a new approach for developing stress fields and truss models based on the finite element method.

A computer program has been developed implementing the ideas of this paper with both research and educational purposes and has been integrated as an applet into an educational web site (http://i-concrete.epfl.ch/). Its source code is freely available and can be downloaded together with the examples contained in this paper.

\section{RESEARCH SIGNIFICANCE}

This paper presents an innovative approach for the automatic development of stress fields using the finite element method. This approach overcomes most of the problems presented by the current methods developed with the same purpose. This technique can be used to obtain suitable stress fields for practical design purposes and is also a helpful tool when investigating the actual load-carrying mechanism of complex structures.

\section{CRITICAL REVIEW OF EXISTING METHODS FOR DEVELOPING TRUSS MODELS AND STRESS FIELDS}

As previously introduced, Schlaich et al. ${ }^{11}$ presented a method for developing truss models named the strut-and-tie

(a)

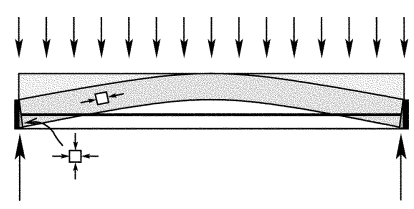

Fig. 1-Stress fields proposed by Drucker ${ }^{3}$ for simplysupported beam under: (a) uniform load; and (b) point load.

ACI Structural Journal, V. 104, No. 4, July-August 2007.

MS No. S-2006-256 received June 19, 2006, and reviewed under Institute publication policies. Copyright (C) 2007, American Concrete Institute. All rights reserved, including the making of copies unless permission is obtained from the copyright proprietors. Pertinent discussion including author's closure, if any, will be published in the May-June 2008 ACI Structural Journal if the discussion is received by January 1, 2008. 
Miguel Fernández Ruiz is a Postdoctoral Fellow at the Ecole Polytechnique Fédérale de Lausanne (EPFL), Lausanne, Switzerland. He received his diploma in civil engineering and his PhD from the Polytechnical University of Madrid, Madrid, Spain, in 2001 and 2004, respectively. His research interests include the serviceability behavior of structures, bond, and the modeling of the behavior of concrete structures using stress fields.

ACI member Aurelio Muttoni is a Professor and Head of the Structural Concrete Laboratory at EPFL. He received his diploma and PhD in civil engineering from the Swiss Federal Institute of Technology, Zurich, Switzerland, in 1982 and 1989, respectively. His research interests include the theoretical basis of the design of reinforced concrete structures, shear and punching shear, fiber-reinforced high-strength concrete, soilstructure interaction, and the conceptual design of bridges. (a)

(c)

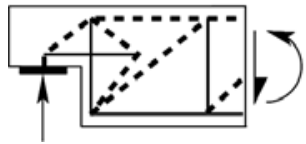

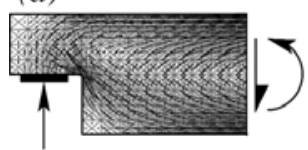

(b)

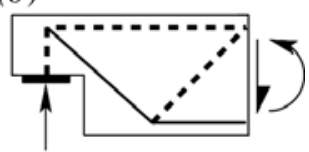

(d)

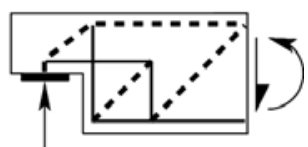

Fig. 2-Dapped-end beam: (a) linear elastic (uncracked) stress field; (b) possible truss model inspired in elastic stress field; and (c) and (d) truss models corresponding to usual reinforcement layouts. (a)

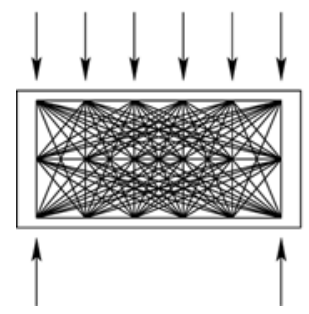

(b)

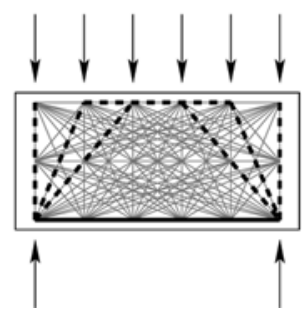

Fig. 3-Development of truss model by optimization of ground truss: (a) ground truss with all possible bars; and (b) resulting truss model after optimization process.

model. According to Schlaich et al., ${ }^{11}$ a strut-and-tie model can be developed for a given element based on its linear elastic (uncracked) stress field, used to identify from it a possible resisting truss model.

The guidance provided by the elastic stress field ensures a good behavior at the serviceability limit state and can also be used to study its ultimate limit state response. This procedure is easy and straightforward for some cases but not for others, depending for instance on the actual reinforcement layout (as inclined reinforcement is typically necessary to follow the elastic uncracked flow of stresses, but an orthogonal reinforcement is often preferred in real structures). For instance, Fig. 2 presents a classical problem where the reinforcement layout developed on the basis of an elasticallyinspired truss model (refer to Fig. 2(a) and (b)) does not correspond to the commonly used reinforcement details (obtained from different truss models Fig. 2(c) and (d)).

For cases in which various truss models (different from the elastically-inspired one) are possible, Schlaich adopts a criterion based on the minimum of complementary strain energy of the system $^{15}$ to decide which one is the most suitable truss model

$$
\sum F_{i} \ell_{i} \varepsilon_{i}=\text { Minimum }
$$

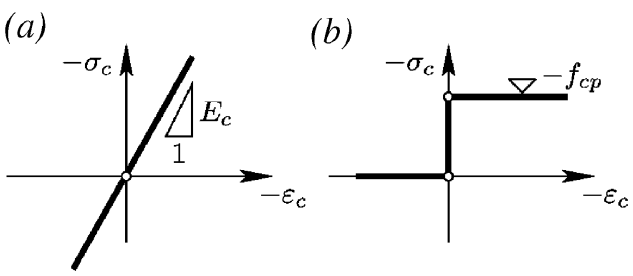

Fig. 4-Comparison of uniaxial stress-strain laws for concrete: (a) linear elastic (with tensile strength); and (b) rigid-plastic without tensile strength.

where $F_{i}$ is the force in each member $i, \ell_{i}$ is the length of the member, and $\varepsilon_{i}$ is the strain in the member.

This criterion allows choosing a truss model from various possibilities, but it does not give information on the actual behavior at the serviceability limit state, considering that the reinforcement layout may differ noticeably from the elastically inspired one.

To sum up, although developing truss models based on the elastic flow of stresses is very satisfying for some cases, it needs to be improved for others. Furthermore, the stress field in a body (and consequently its overall behavior) depends on the actual reinforcement layout and is thus not exclusively determined by its geometry and load pattern. This is justified because tensile forces carried by the reinforcing steel are necessary to ensure the internal equilibrium. Consequently, the reinforcement layout influences the resulting stress field within the body.

Another systematic approach for the choice of a suitable truss model is presented in Ali and White, ${ }^{13}$ where an optimization process is performed choosing a truss model from a ground truss satisfying certain criteria (refer to Fig. 3). This approach allows the consideration of a predefined reinforcement layout, because the nodes and the elements of the ground truss can be placed according to the desired reinforcement layout. Also, elasto-plastic considerations on the behavior of the members can be implemented. Questions arise, however, on the cross sectional area to be attributed to each compression member, especially if more than one element can carry the load at a given node: the physical reality is a continuum and not a set of bars.

The stress field method has traditionally been based on the assumption of a rigid-plastic stress-strain law without tensile strength for the concrete ${ }^{12}$ (in contrast to the linear elastic uncracked law on which the analyses of Schlaich et al. ${ }^{11}$ are based, refer to Fig. 4). Neglecting the tensile strength of concrete requires placing a minimal amount of reinforcement for crack control to ensure a satisfactory behavior of the structure. This reinforcement ensures that no brittle failure occurs at cracking and that the cracks are suitably smeared over the element at the serviceability limit state.

The development of stress fields with the previous assumptions ${ }^{12}$ allows a great freedom in the choice of the load-carrying mechanism of a structure. This freedom, however, may be excessive in some cases. For instance, Fig. 5 shows three possible stress fields for the same given situation. Although all of them require the same amount of reinforcement, checking of the concrete stresses requires a detailed study of the compressive stress field. In these cases (as well as for the development of stress fields in unusual cases), a certain level of experience is required for the choice of the most suitable stress field and to asses its applicability. For example, the stress fields shown in Fig. 1 and developed 
by Drucker were later found not to be suitable for some situations, depending on the slenderness of the beam, ${ }^{7,16}$ as cracks forming near the lower tie may seriously limit the strength of the compression field.

Muttoni et al. ${ }^{12}$ proposed a general procedure for developing stress fields considering also their serviceability behavior. This method is based on the choice of a load-carrying mechanism for the structure and on the control of the opening of critical cracks. Although the method is completely general, it requires a trial-and-error procedure that is difficult to implement in a general way and may also require a certain level of experience for the choice of the load-carrying mechanisms.

Further problems for the application of stress fields are found in the value of the effective concrete strength (to account for the effect of cracking) and in the actual ductility of the structural member (that cannot be determined using a rigid-plastic material behavior). Concerning the former, Vecchio and Collins ${ }^{17}$ developed a complete theory named the modified compression field theory that is suitable to be applied to compression fields including the effect of transverse strains of concrete. The latter is a question that remains open.

\section{FINITE ELEMENT MODEL ANALYSIS OF STRESS FIELDS}

The automatic generation of stress fields for structural concrete is investigated in this section with the help of the finite element (FE) method, implementing the main hypotheses of the stress field method. ${ }^{12}$

This approach overcomes most of the previously described limitations found when a truss model or stress field is developed on the basis of an elastic uncracked analysis. Furthermore, only a limited number of parameters with a clear physical meaning are required (strength and modulus of elasticity) in contrast to more refined FE models that may improve some aspects but require the definition of many additional parameters, which may be difficult to measure or quantify.

The behavior for the concrete can be understood with the help of Fig. 6. Given a displacement field over the continuum, its corresponding strain field can be determined (Fig. 6 (a) to (c)). In this work, the principal stress directions are assumed parallel to the principal strain directions and their values are obtained from them (this hypothesis is classical in the development of stress fields).

The principal stresses are then computed from the principal strains as

$$
\sigma_{i}=\sigma_{i}\left(\varepsilon_{i}, \varepsilon_{j}\right)
$$

The concrete stress-strain response is considered elasticperfectly plastic in compression and the tensile strength of concrete is neglected (refer to Fig. 6(e)). Both assumptions are in accordance with the hypotheses of the stress field method.

The elastic modulus of concrete $E_{c}$ is adopted as the secant modulus of the material. This value is considered independent of its transverse strain state as proposed in Vecchio et al. ${ }^{18}$

The compressive strength of concrete is adopted as the concrete equivalent plastic strength, ${ }^{12}$ corrected by a parameter $\eta\left(\varepsilon_{j}\right)$ dependent on the transverse strain

$$
f_{c p}=3.1\left(f_{c}^{\prime}\right)^{2 / 3} \cdot \eta\left(\varepsilon_{j}\right)
$$

where $f_{c}^{\prime}$ is the cylinder compressive strength of concrete in $\mathrm{MPa}(1 \mathrm{MPa}=6.9 \mathrm{ksi})$. Several studies have been performed (a)
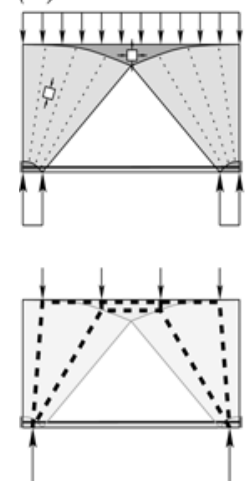

(b)
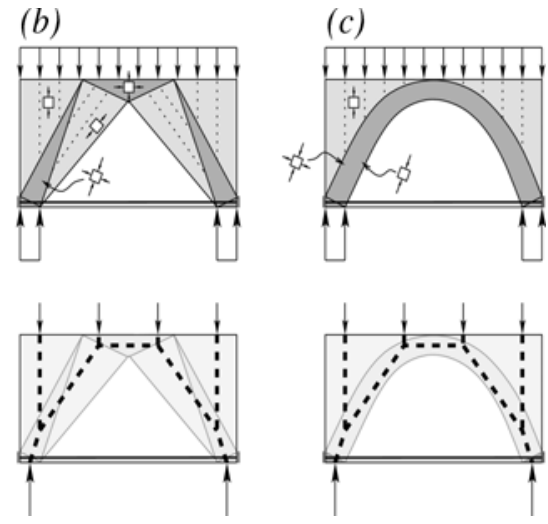

Fig. 5-Three different stress fields admissible for same problem and their corresponding truss models: (a) fanshaped stress field; (b) wedge-shaped stress field; and (c) arch-shaped stress field.
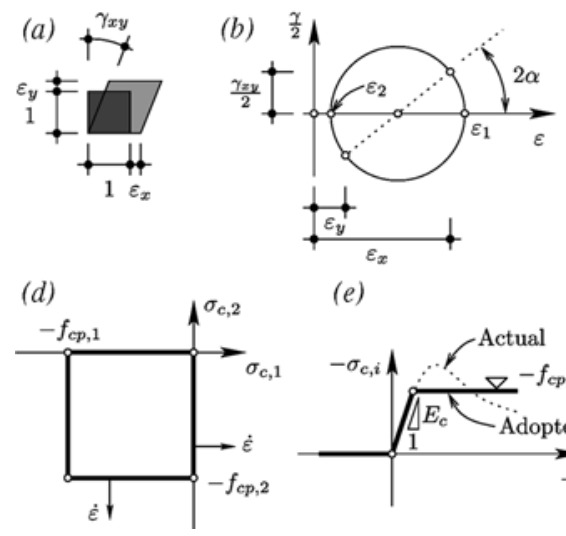

(e)

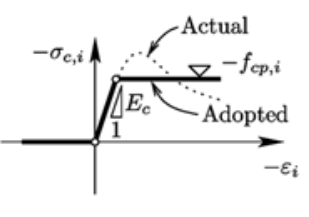

(c)

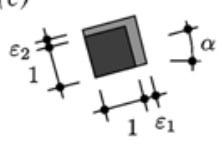

(f)

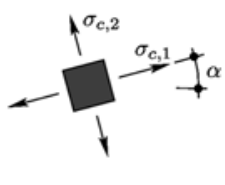

Fig. 6-Concrete modeling: (a) strains; (b) Mohr's circle and principal strains; (c) directions of principal strains; $(d)$ adopted yield surface for plane stress and associative flow rule; (e) actual and adopted (elastic-perfectly plastic) stress-strain response; and $(f)$ assumed directions for principal stresses.

on the influence of the transverse strains $\eta\left(\varepsilon_{j}\right)$ in the concrete strength, leading to various models ${ }^{17,19-21}$ that, in general, provide similar results. For instance, according to Hars, ${ }^{21}$ this parameter can be evaluated using

$$
\eta\left(\varepsilon_{j}\right)=\frac{1}{0.9+30\left(f_{c}^{\prime}\right)^{1 / 3} \varepsilon_{j}} \leq 1.0
$$

where $f_{c}^{\prime}$ is the compressive strength of concrete in MPa (6.90 $\mathrm{MPa}=1 \mathrm{ksi})$.

The previously described behavior of concrete corresponds in fact to a Mohr-Coulomb yield surface with a tension cut-off and an associative flow rule (refer to Fig. 6(d)), where the effect of the transverse strains $\eta\left(\varepsilon_{j}\right)$ can be interpreted as a contraction in the yield surface with increasing positive transverse strains.

The FE model implementation of this behavior can be performed using various elements that allow to approximate the strain field for a given displacement field. For instance, Fig. 7 presents the application of the previous ideas on a constant strain triangle where the nodal forces can be obtained as 

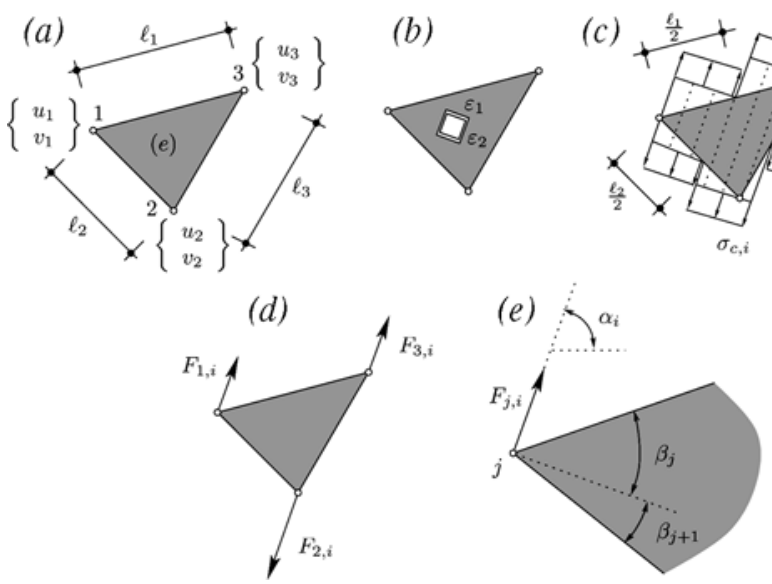

Fig. 7-Constant strain triangle: (a) displacement field in element; (b) strain field in element; (c) assumed stress field for principal stress i; (d) nodal forces; and $(e)$ angle $\beta$ at each node $\mathrm{j}$.

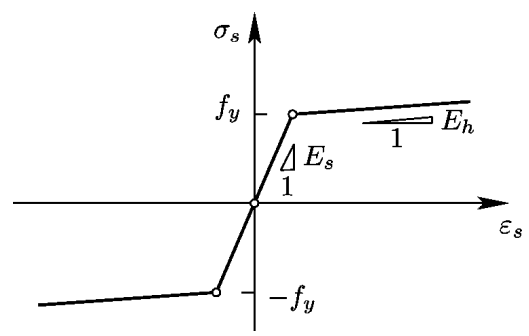

Fig. 8-Reinforcing and prestressing steel. Elasto-plastic behavior with strain hardening.

$$
\begin{gathered}
F_{j, i}=\sigma_{i}\left(\frac{\ell_{j}}{2} \cos \left(\beta_{j}\right)-\frac{\ell_{j+1}}{2} \cos \left(\beta_{j+1}\right)\right) \\
\text { for } i \in(1,2) \text { and } j \in(1,2,3)
\end{gathered}
$$

The behavior of the reinforcing steel (refer to Fig. 8) is modeled by a uniaxial response (neglecting dowel action), with a bilinear elasto-plastic law with strain hardening (and an associative flow rule). Its response is defined by the yield strength of the material $f_{y}$, its elastic modulus $E_{s}$, and its hardening modulus $E_{h}$. This behavior is implemented using a one-dimensional link element as shown in Fig. 9 where its nodal forces can be obtained as

$$
F_{i}=\sigma_{s} A_{s, i}
$$

where $A_{s, i}$ is the cross section of the bar. Prestressing, if any, is introduced as an initial self-induced strain in the member.

These elements have been implemented into an objectoriented computer program developed by the authors. The nonlinear set of equations is solved assembling the tangent stiffness matrix and using a full Newton-Raphson algorithm as solver. Excellent robustness and speed of convergence have been found with this technique for all the cases investigated.

\section{PRACTICAL METHODOLOGY FOR DEVELOPING STRESS FIELDS AND TRUSS MODELS}

The application of the FE model to develop stress fields is direct when an existing structure or element needs to be (a)
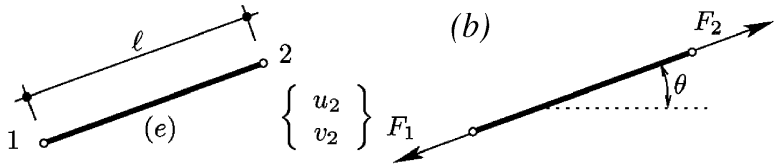

$\left\{\begin{array}{l}u_{1} \\ v_{1}\end{array}\right\}$

Fig. 9-Link element: (a) displacement field at element; and (b) nodal forces.

checked. When a new structural member is to be designed, however, a three-step procedure is proposed:

1. First, an FE trial model is developed with a reinforcement layout based on the experience of the designer or, alternatively, using an orthogonal uniformly distributed reinforcement layout corresponding to the minimal reinforcement amount for crack control. The concrete is considered elasto-plastic with no tensile strength as previously described. The steel, however, is considered perfectly-elastic;

2. The FE model is solved using the actual loads. The resulting state of stresses is studied and a stress field is developed on its basis. A truss model can additionally be developed if necessary, taking advantage of the forces obtained in the various members of the stress field. The reinforcement can be dimensioned from the FEM results by modifying the initial reinforcement in the element $\left(A_{s, \text { min }}\right)$ considering the stress obtained from the FEM analysis $\sigma_{s}$ and its design yield strength $f_{y d}$

$$
A_{s}=A_{s, \min } \frac{\sigma_{s}}{f_{y d}} \geq A_{s, \min }
$$

Consequently, the force in the element remains unchanged and the value of $A_{s}$ will be larger or equal to the minimal reinforcement amount; and

3 . The geometry and reinforcement layout of the element are adjusted on the basis of the previous results and a new FE model analysis (considering the steel as elasto-plastic this time) is performed to check the overall performance of the structure.

\section{EXAMPLES OF APPLICATIONS}

This section presents two examples of application of the FE model. In the first one, it is used to check the response of two existing structural members. In the second example, a suitable stress field and its corresponding truss model for the design of a new element are investigated.

\section{Checking strength of existing members- application to deep beams}

Figure 10 shows deep beams WT4 and WT7 tested by Leonhardt and Walther. ${ }^{22}$ The ultimate load obtained with the FE model for specimen WT4 is $1.59 \mathrm{MN}$ (355 kips) (96\% of the actual strength) and $1.13 \mathrm{MN}$ (252 kips) for specimen WT7 (99\% of the actual strength).

The FE model concrete stress fields for walls WT4 and WT7 are shown in Fig. 11(b) and (e). It is interesting to compare these stress fields with those shown in Fig. 5. A load on top of the beam activates mainly a fan action with a biaxial compression zone on top of the wall. In contrast, a load on the bottom of the beam activates mainly an arching action (refer to Fig. 11(c) and (f)). This result agrees with the minimum of complementary strain energy criterion provided 
(a)
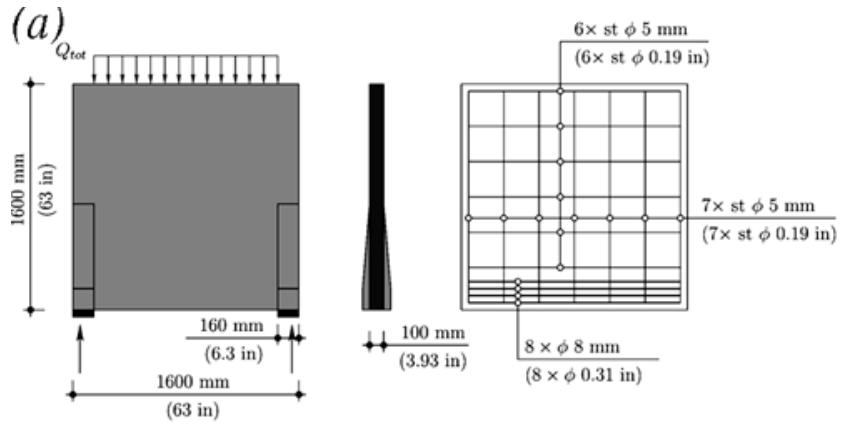

(b)
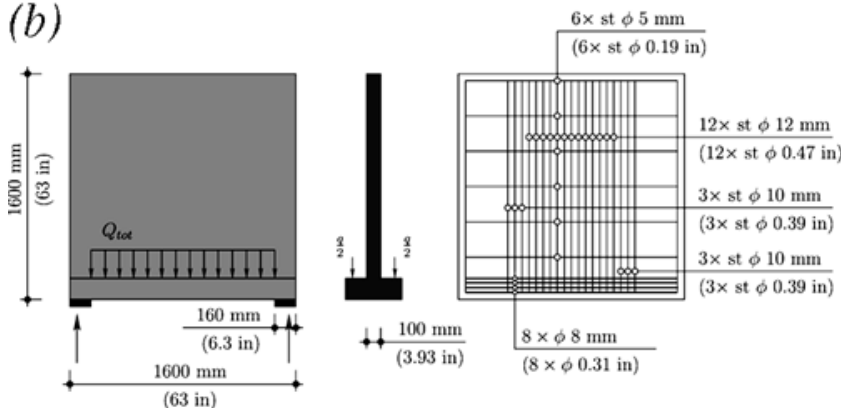

Fig. 10-Geometry and reinforcement layout for deep Beams WT4 and WT7 ${ }^{22}\left(\mathrm{f}_{\mathrm{y}}=419 \mathrm{MPa}[60.7 \mathrm{ksi}]\right.$ and $\mathrm{E}_{\mathrm{s}}=$ 205,000 MPa [29,800 ksi]): (a) WT4 ( $\mathrm{f}_{\mathrm{c}}=28 \mathrm{MPa}[4.1 \mathrm{ksi}]$ and $\left.\mathrm{E}_{\mathrm{c}}=31,000 \mathrm{MPa}[4490 \mathrm{ksi}]\right) ;$ and (b) WT7 $\left(\mathrm{f}_{\mathrm{c}}=30 \mathrm{MPa}\right.$ [4.3 ksi] and $\mathrm{E}_{\mathrm{c}}=31,000 \mathrm{MPa}[4490 \mathrm{ksi}]$ ).

Table 1-Forces in ties for truss model of Fig. 14 according to proposed approach

\begin{tabular}{c|c}
\hline Element & $F$, MN (kips) \\
\hline$T_{1 d}$ & $0.64(142)$ \\
\hline$T_{2 d}$ & $0.44(98.2)$ \\
\hline$T_{3 d}$ & $0.27(60.3)$ \\
\hline$T_{4 d}$ & $0.21(46.9)$ \\
\hline$T_{5 d}$ & $0.06(13.4)$ \\
\hline$T_{6 d}$ & $0.76(169)$ \\
\hline$T_{7 d}$ & $0.36(80.4)$ \\
\hline$T_{8 d}$ & $0.40(89.3)$ \\
\hline$T_{9 d}$ & $1.01(225)$ \\
\hline$T_{10 d}$ & $0.40(89.3)$ \\
\hline
\end{tabular}

by Kupfer and previously discussed. It can be noticed that in the load-deflection curve (Fig. 11(g)), the tension-stiffening effect is neglected according to the hypotheses adopted, leading to an overestimation of the deflections in the uncracked and crack-development stages. A reasonable estimate of the deflection, however, is obtained at higher load levels.

\section{Dimensioning of structural member-application to deep beam with opening}

Figure 12 shows the geometry of a deep beam with an opening studied by Schlaich et al. ${ }^{11}$ The results obtained considering an orthogonal reinforcement layout and using the FE approach proposed in this paper are shown in Fig. 13. From these results, it is straightforward to develop the corresponding stress field (Fig. 14 (a)), truss model (Fig. 14 (b)) and a suitable reinforcement layout (Fig. 14 (c)). Concerning the anchorage of the bars, the position where stirrups and hooks have to be placed can be directly determined, as well as which (a)

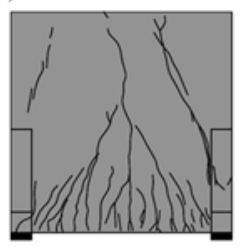

(d)

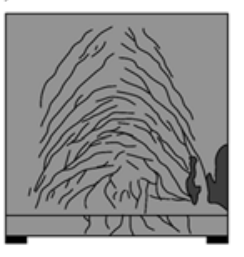

(b)

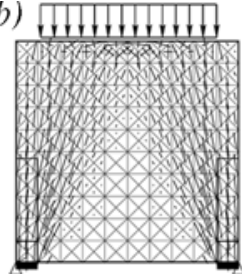

(e)

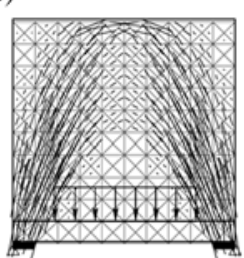

(f)
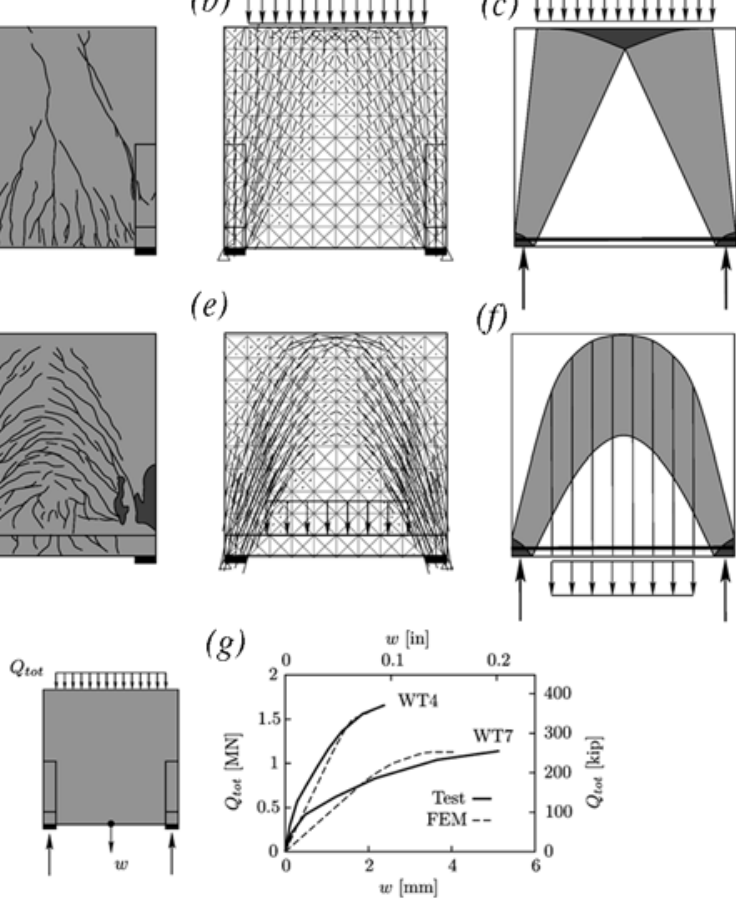

Fig. 11-Deep Beams WT4 and WT $7^{22}$ : (a) WT4 (after failure); (b) FE model plot of concrete principal compressive stress directions for deep Beam WT4; (c) stress field for deep Beam WT4; (d) WT7 (after failure); (e) FE model plot of concrete principal compressive stress directions for deep Beam WT7; $(f)$ stress field for deep Beam WT7; and $(g)$ comparison of measured/computed deflection at midspan for both deep beams.

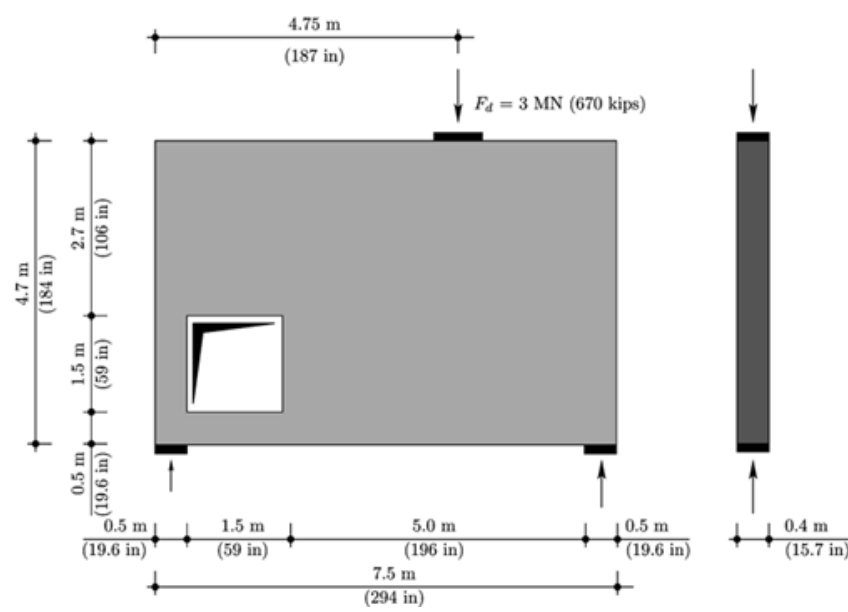

Fig. 12-Main dimensions of studied deep beam with opening (geometry according to example presented in Schlaich et al. ${ }^{11}$ ).

bars can be anchored by bond. The forces in the tensile members are detailed in Table 1.

These results can be compared with those proposed by Schlaich et al. ${ }^{11}$ and shown in Fig. 15 (numerical values are given in Table 2). It can be noticed that sizeable differences appear in the reinforcement layout.

For instance, according to Schlaich et al., ${ }^{11}$ the horizontally distributed reinforcement is not used to anchor the fan of compressive stresses going to the right support. Also, the beam below the opening is not used to transmit a fraction of the load to the left support. The placing of reinforcement in 


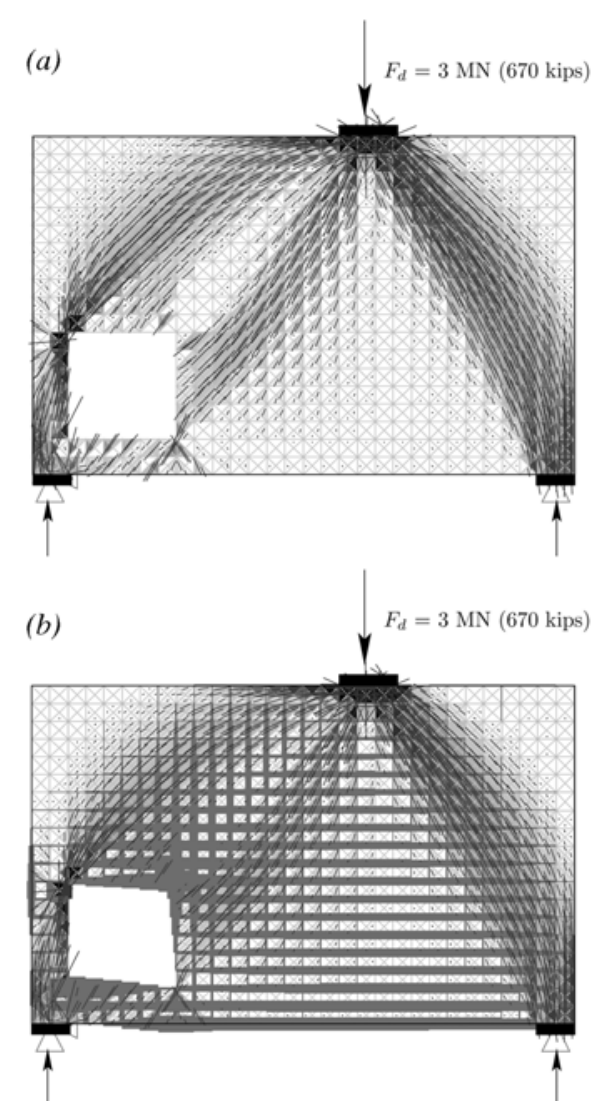

Fig. 13-Nonlinear FE model results for deep beam with opening: (a) plot of concrete principal compressive stress directions; and (b) plot of steel forces superimposed to previous plot.

Table 2-Forces in ties for truss model of Fig. 15 according to Schlaich et al. ${ }^{11}$

\begin{tabular}{c|c}
\hline Element & $F$, MN (kips) \\
\hline$T_{1 s, d}$ & $1.07(239)$ \\
\hline$T_{2 s, d}$ & $0.53(118)$ \\
\hline$T_{3 s, d}$ & $0.53(118)$ \\
\hline$T_{4 s, d}$ & $0.53(118)$ \\
\hline$T_{5 s, d}$ & $1.07(239)$ \\
\hline$T_{6 s, d}$ & $1.07(239)$ \\
\hline$T_{7 s, d}$ & $0.53(118)$ \\
\hline$T_{8 s, d}$ & $0.53(118)$ \\
\hline$T_{9 s, d}$ & $0.66(147)$
\end{tabular}

this element seems advisable, however, to ensure a suitable cracking pattern. Tests results by Maxwell and Breen ${ }^{23}$ confirmed this point and also shown an increase in the strength of the member. Furthermore, the lower tie is not used to center the resultant of the compressive stresses of the beam at the left of the opening.

In the reinforcement layout, according to Schlaich et al., ${ }^{11}$ very heavy ties are disposed. Following the approach proposed in this paper, however, the reinforcement is smeared, taking advantage of the minimal reinforcement that is present in all cases. Considering the FE model results, it should be said that placing a certain amount of inclined reinforcement at the upper-right corner of the hole, however, seems advisable to control cracking in that region. (a)

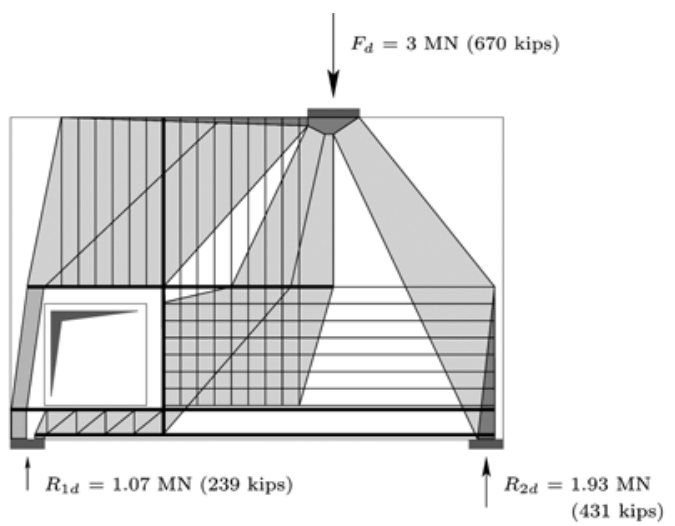

(b)
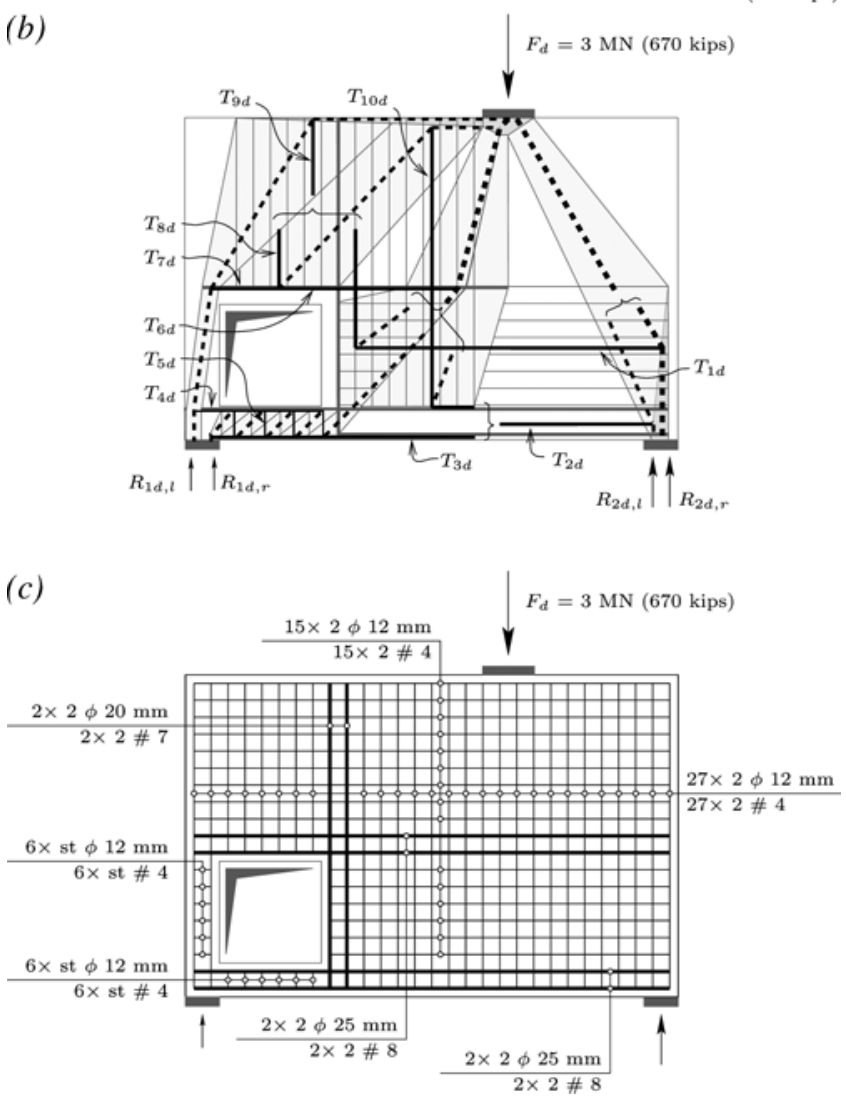

Fig. 14-Dimensioning of deep beam according to FE results: (a) adopted stress field; (b) resulting truss model and main values; and (c) proposed reinforcement layout $\left(\mathrm{f}_{\mathrm{yd}}=\right.$ $434 \mathrm{MPa}[62.2 \mathrm{ksi}])$.

\section{FURTHER RESEARCH}

Currently, research is being carried on the applicability of certain algorithms for the automatic development of suitable reinforcement layouts. ${ }^{24}$ This approach, combined with the FE model introduced in this paper, will allow optimizing some design criteria (for example, crack width and failure load) in the dimensioning and detailing of a structural member.

\section{CONCLUSIONS}

This paper investigates the development of suitable stress fields and their corresponding truss models for structural concrete. A general procedure for implementing the hypotheses of the stress field method using the FE method is proposed. With this approach, usual and unusual cases can be systematically investigated, considering the actual reinforcement layout and the concrete nonlinear behavior. 
(a)
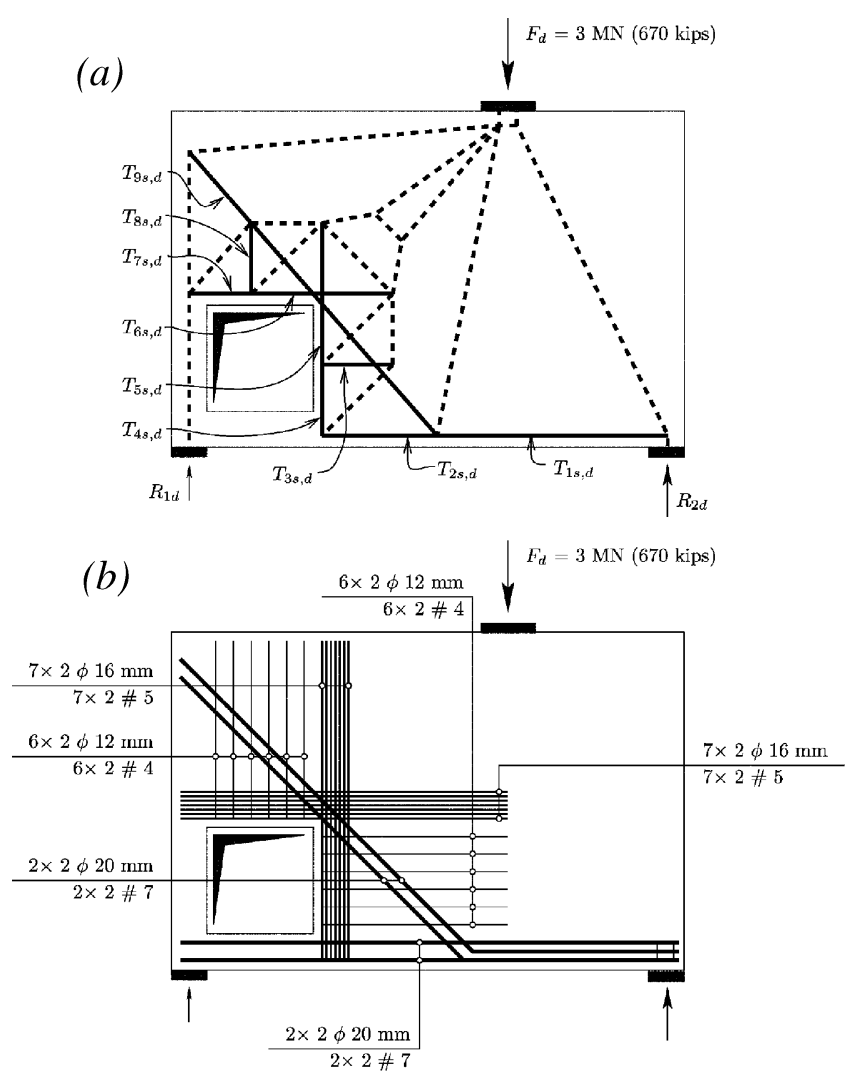

Fig. 15 -Dimensioning of deep beam according to Schlaich et al. ${ }^{11}$ : (a) adopted truss model and main values; and (b) reinforcement layout.

The main conclusions of this paper are:

1. The stress state of a structural member at the ultimate limit state may differ noticeably from the stress state obtained from an uncracked elastic analysis of the continuum (furthermore, if the influence of the reinforcement layout is not considered). Thus, an elastic uncracked approach may be difficult to follow for some cases, limiting also the freedom of choice for the reinforcement layout for others;

2. Truss models based on a truss optimization may overcome some of the previous problems. However, the choice of the cross-sectional area that has to be attributed to each compression member in this analysis is not yet completely solved (partly because a structural concrete member is a continuum and not a set of bars);

3. A nonlinear FE analysis considering the hypotheses of the stress field method allows a step forward in this direction. Starting from a reasonable amount of physical parameters, a suitable stress fields is obtained (from which an equivalent truss model can be derived);

4. The influence of certain effects (for example, the decrease in the concrete compressive strength due to its transverse strain state) is also locally introduced;

5. This tool can be used alone, but it is more interesting to use it as a guide to develop (by hand) stress fields and their corresponding truss models, giving more freedom of choice to the designer; and

6. This tool becomes especially interesting when the behavior of a complex or unusual stress field is studied, although it can be used to investigate the behavior of classical cases.

\section{NOTATION}

$A_{s} \quad=$ steel cross-sectional area

$A_{s, \min }=$ minimal reinforcement amount for crack control

$E_{c}=$ modulus of elasticity of concrete

$E_{h} \quad=$ hardening modulus of steel

$E_{S} \quad=$ modulus of elasticity of steel

$F \quad=$ force

$F_{d}=$ dimensioning force

$F_{h}=$ horizontal force

$F_{j, i}=$ nodal force in node $j$ for principal stress direction $i$

$F_{v}=$ vertical force

$f \quad=$ nodal force

$f_{c 0}=$ concrete reference strength in compression

$f_{c}{ }^{\prime}=$ concrete uniaxial strength in compression

$f_{c p}=$ concrete uniaxial equivalent plastic strength in compression

$f_{y} \quad=$ yield strength of reinforcement

$f_{y d}=$ dimensioning yield strength of reinforcement

$\ell=$ length of element

$Q_{\text {tot }}=$ total applied load

$u=$ horizontal displacement

$v \quad=$ vertical displacement

$w \quad=$ deflection at midspan

$\alpha=$ principal stress angle with horizontal axis

$\beta=$ nodal force angle

$\delta=$ horizontal displacement

$\varepsilon=$ strain

$\varepsilon_{1}, \varepsilon_{2}=$ principal strains

$\gamma_{x y}=$ shear strain

$\eta=$ concrete compressive strength reduction parameter

$\theta=$ steel element angle with horizontal axis

$\sigma \quad=$ stress

$\sigma_{1}, \sigma_{2}=$ principal stresses

$\sigma_{c}=$ concrete stress

$\sigma_{s} \quad=$ steel stress

\section{REFERENCES}

1. Ritter, W., "The Hennebique Construction Method," ("Die Bauweise Hennebique”), Schweizerische Bauzeitung, V. XXXIII, No. 7, 1899, pp. 41-61. (in German)

2. Mörsch, E., Reinforced Concrete Construction, Theory and Application (Der Eisenbetonbau, seine Theorie und Andwendung), 3rd Edition, Verlag von Konrad Wittwer, 1908, 376 pp. (in German)

3. Drucker, D. C., "On Structural Concrete and the Theorems of Limit Analysis," Publications, V. 21, International Association for Bridge and Structural Engineering, Zürich, 1961, pp. 49-59.

4. Thürlimann, B.; Marti, P.; Pralong, J.; Ritz, P.; and Zimmerli, B., "Application of the Plasticity Theory to Reinforced Concrete," ("Anwendung der Plastizitätstheorie auf Stahlbeton”), Institut für Baustatik und Konstruction, ETH Zürich, 1983, 252 pp. (in German)

5. Müller, P., "Plastic Calculus of Reinforced Concrete Disks and Beams," ("Plastische Berechnung von Stahlbetonscheiben und-balken"), Institut für Baustatik und Konstruction, Bericht, No. 83, ETH Zürich, 1978, 160 pp. (in German)

6. Marti, P., "On the Plastic Analysis of Reinforced Concrete," ("Zur plastischen Berechnung von Stahlbeton"), Institut für Baustatik und Konstruction, Bericht, No. 104, ETH Zürich, 1980, 175 pp. (in German)

7. Muttoni, A., "The Applicability of the Theory of Plasticity in the Design of Reinforced Concrete," ("Die Andwendbarkeit der Plastizitätstheorie in der Bemessung von Stahlbeton”), Institut für Baustatik und Konstruction, Bericht, No. 176, ETH Zürich, 1989, 159 pp. (in German)

8. Nielsen, M. P.; Braestrup, M. W.; Jensen, B. C.; and Bach, F. "Concrete Plasticity, Beam Shear-Shear in Joints-Punching Shear," Special Publication, Danish Society for Structural Science and Engineering, 1978, 129 pp.

9. Nielsen, M. P., Limit Analysis and Concrete Plasticity, 2nd Edition, CRC Press, 1999, 908 pp.

10. Schlaich, J., and Weischede, D., "A Practical Method for Methodical Design and Building in Reinforced Concrete," ("Ein praktisches Verfahren zum methodischen Bemessen und Konstruieren im Stahlbetonbau"), Bulletin d'Information, No. 150, Comité Euro-International du Béton, 1982, 163 pp.

11. Schlaich, J.; Schäfer, K.; and Jennewein, M., "Toward a Consistent Design of Structural Concrete," Prestressed Concrete Institute Journal, May-June 1987, pp. 75-150.

12. Muttoni, A.; Schwartz, J.; and Thürlimann, B., Design of Concrete Structures with Stress Fields, Birkhaüser, Basel, Boston and Berlin, Switzerland, 1997, 145 pp.

13. Ali, M. A., and White, R. N., "Automatic Generation of Truss Model for Optimal Design of Reinforced Concrete Structures," ACI Structural 
Journal, V. 98, No. 4, July-Aug. 2001, pp. 431-442.

14. Despot, Z., "Finite Element Method and Plasticity Theory for the Dimensioning of Reinforced Concrete Disks," ("Methode der finiten Elemente und Plastizitätstheorie zur Bemessung von Stahlbetonscheiben"), PhD thesis, ETH Zürich, 1995, 121 pp. (in German)

15. Kupfer, H., "Shear Security According to Mörsch," ("Die Schubsicherung nach Mörsch”), Bulletin d'Information, No. 40, Comité Européen du Béton, 1964, pp. 45-57. (in German)

16. Kani, G., "The Riddle of Shear Failure and its Solution," ACI JournaL, Proceedings V. 61, No. 4, Apr. 1964, pp. 441-467.

17. Vecchio, F. J., and Collins, M. P., "The Modified Compression Field Theory for Reinforced Concrete Elements Subjected to Shear,' ACI JOURNAL, Proceedings V. 83, No. 2, Mar.-Apr. 1986, pp. 219-231.

18. Vecchio, F. J.; Collins, M. P.; and Aspiotis, J., "High-Strength Concrete Elements Subjected to Shear," ACI Structural Journal, V. 91, No. 4, JulyAug. 1994, pp. 423-433.

19. Vecchio, F. J., "Disturbed Stress Field Model for Reinforced Concrete: Formulation," Journal of Structural Engineering, ASCE, V. 126, No. 9 ,
Sept. 2000, pp. 1070-1077.

20. Kaufmann, W., "Strength and Deformations of Structural Concrete Subjected to In-Plane Shear and Normal Forces" Institut für Baustatik und Konstruction, Bericht, No. 234, ETH Zürich, 1998, 145 pp.

21. Hars, E., "Shear Strength of Reinforced and Prestressed Concrete Girders with Thin Webs," ("Zum Querkraftwiderstand von Stahl-und Spannbetonträgern mit dünnen Stegen"), PhD thesis, Ecole Polytechnique Fédérale de Lausanne, Switzerland, 2006, 144 pp. (in German)

22. Leonhardt, F., and Walther, R., "Deep Beams," ("Wandartige Träger"), Deutscher Ausschuss für Stahlbeton, No. 178, Berlin, Germany, 1966, 159 pp. (in German)

23. Maxwell, B. S., and Breen, J. E., "Experimental Evaluation of Strutand-Tie Model Applied to Deep Beam with Opening," ACI Structural Journal, V. 97, No. 1, Jan.-Feb. 2000, pp. 142-148.

24. Kostic, N., and Muttoni, A., "Computer-Based Development of Stress Fields," 6th International PhD Symposium in Civil Engineering, Zürich, 2006, pp. 85-86. 